\title{
Quantifying the visual information sourced from melanopsin photoreceptors in mouse LGN field responses
}

\author{
Sohail Siadatnejad*, Timothy M Brown, John Gigg, Hugh D Piggins, Robert J Lucas, Marcelo A Montemurro \\ From Twentieth Annual Computational Neuroscience Meeting: CNS*2011 \\ Stockholm, Sweden. 23-28 July 2011
}

Melanopsin photoreceptors make a third type of photoreceptor along with rods and cones in human and mouse. Until recently melanopsin was thought to participate only in subconscious responses to light (such as pupillary reflexes and regulating the circadian rhythm) and not in image-forming visual responses. Recently, it has been shown that melanopsin derived signals are also widespread in image-forming visual pathways of mice [1]. The goal of this study is to quantify their contribution in the visual pathway. We used information theoretic measures [2,3] on field potentials [3] to quantify the amount of information that is originated in melanopsin
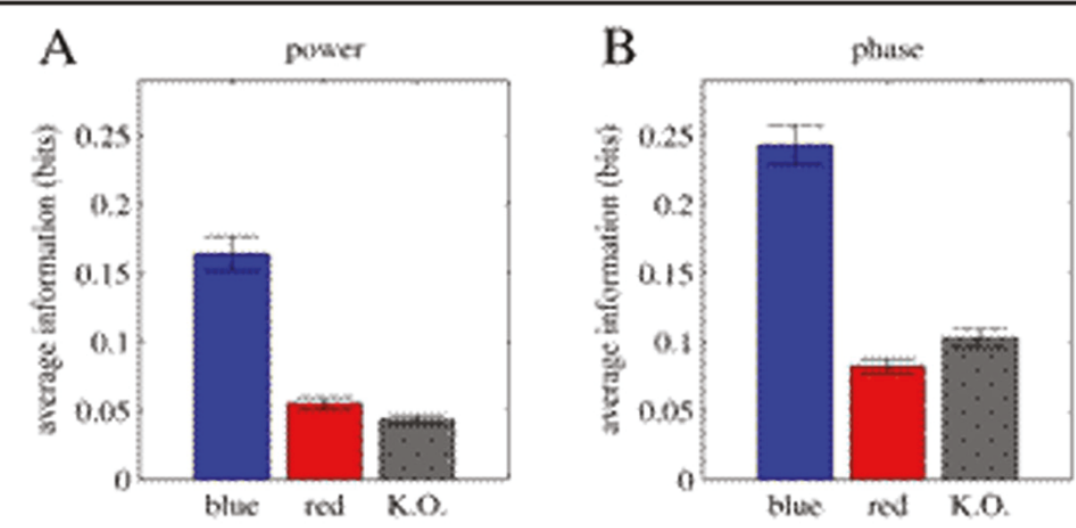

Figure 1 Quantification of melanopsin information. Information estimated for responses to blue and red are averaged and shown with SEM (averaged over total 372 channels that lay in LGN for 17 animals). Information in response to blue light is on average greater than the information estimated in responses of the same units to red light. Panel A shows this information comparison for power and B for phase of field potentials recorded in each channel. The power and phase response values were discretized into four levels for information estimations. A. Power of the $20-24 \mathrm{~Hz}$ band of field potentials at $45-50$ msec after light onset. B. Phase of the $20-24 \mathrm{~Hz}$ band at $45-50$ msec after light onset. The third column labelled K.O. shows the information found in responses to blue light in melanopsin knock out mice (396 channels, 17 animals). Since they genetically lack melanopsin they are used to confirm the amount of visual information that is lacked when melanopsin is not activated.

\footnotetext{
* Correspondence: sohail.siadatnejad@postgrad.manchester.ac.uk

Faculty of Life Sciences, University of Manchester, Manchester, M13 9PT, UK

Full list of author information is available at the end of the article
} 
photoreceptors. The continuous field potentials were recorded from lateral geniculate nucleus (LGN) of transgenic mice $\left(\mathrm{Opn} 1 \mathrm{mw}^{\mathrm{R}}\right)$ [1] using multichannel electrodes.

The role of melanopsin was quantified by estimating the information [2] found in LGN responses, about the intensity of constant blue $(460 \mathrm{~nm})$ and red $(655 \mathrm{~nm})$ light (7 levels of irradiance were used). The intensities of these two lights were carefully matched to provide equal stimulation of the red-sensitive cones of Opn $1 \mathrm{mw}^{\mathrm{R}}$ animals and to control for the influence of rod photoreceptors. Since the long wavelength (red) light was essentially invisible to melanopsin, subtracting the amount of information in $655 \mathrm{~nm}$ stimuli from the $460 \mathrm{~nm}$ should reveal the visual information that is sourced from melanopsin photoreceptors in each recording channel. To investigate the local continuous response signals, the power and phase of recorded field signals were examined at various frequency bands and time points. For each spectrotemporal component of the responses, information about the intensity of light was estimated [1,3] separately for blue and red lights for each recording channel.

The main conclusion is that in different spectrotemporal components of field responses the presence of melanopsin information was confirmed and quantified for both power and phase. Information in response to blue light was significantly higher than red (Fig. 1). Melanopsin influence on the phase of field oscillations was stronger than field power. The results were confirmed in mice that genetically lacked melanopsin photoreceptors [1] (Fig. 1). This confirms that LGN receives visual content through functional pathways that are specifically sourced from melanopsin photoreceptors.

\section{Acknowledgments}

This work was funded by a Wellcome Trust grant to RJL and HDP.

Published: 18 July 2011

\section{References}

1. Brown TM, Gias C, Hatori M, Keding SR, Semo M, Coffey PJ, Gigg J, Piggins HD, Panda S, Lucas RJ: Melanopsin contributions to irradiance coding in the thalamo-cortical visual system. PLOS Biol 2010, 8(12): e1000558.

2. Montemurro MA, Senatore R, Panzeri S: Tight data-robust bounds to mutual information combining shuffling and model selection techniques. Neural Comp 2007, 19:2913-2957.

3. Montemurro MA, Rasch MJ, Murayama Y, Logothetis NK, Panzeri S: Phaseof-firing coding of natural visual stimuli in primary visual cortex. Curr Biol 2008, 18(5):375-80.

doi:10.1186/1471-2202-12-S1-P226

Cite this article as: Siadatnejad et al:: Quantifying the visual information sourced from melanopsin photoreceptors in mouse LGN field responses. BMC Neuroscience 2011 12(Suppl 1):P226.

\section{Submit your next manuscript to BioMed Central and take full advantage of:}

- Convenient online submission

- Thorough peer review

- No space constraints or color figure charges

- Immediate publication on acceptance

- Inclusion in PubMed, CAS, Scopus and Google Scholar

- Research which is freely available for redistribution

Submit your manuscript at www.biomedcentral.com/submit
C BioMed Central 